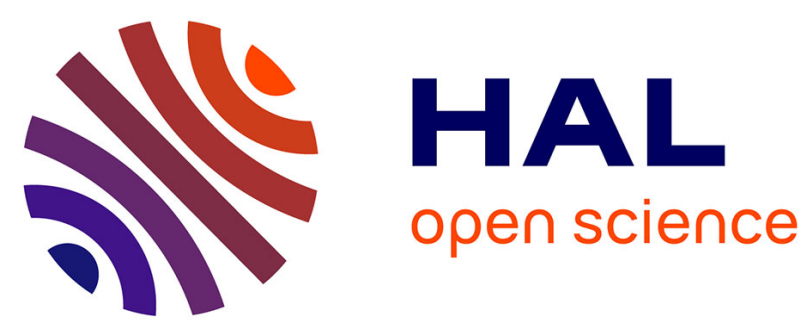

\title{
Quantifying Quality: Towards a Post-humanist Perspective on Sensemaking
}

Eric Monteiro, Thomas Østerlie, Elena Parmiggiani, Marius Mikalsen

\section{To cite this version:}

Eric Monteiro, Thomas Østerlie, Elena Parmiggiani, Marius Mikalsen. Quantifying Quality: Towards a Post-humanist Perspective on Sensemaking. Working Conference on Information Systems and Organizations (IS\&O), Dec 2018, San Francisco, CA, United States. pp.48-63, 10.1007/978-3030-04091-8_5. hal-02083600

\section{HAL Id: hal-02083600 https://hal.inria.fr/hal-02083600}

Submitted on 29 Mar 2019

HAL is a multi-disciplinary open access archive for the deposit and dissemination of scientific research documents, whether they are published or not. The documents may come from teaching and research institutions in France or abroad, or from public or private research centers.
L'archive ouverte pluridisciplinaire HAL, est destinée au dépôt et à la diffusion de documents scientifiques de niveau recherche, publiés ou non, émanant des établissements d'enseignement et de recherche français ou étrangers, des laboratoires publics ou privés. 


\title{
Quantifying quality: Towards a Post-Humanist Perspective on Sensemaking
}

\author{
Eric Monteiro ${ }^{1}$, Thomas $\varnothing_{\text {sterlie }}{ }^{1}$, Elena Parmiggiani ${ }^{1}$ and Marius Mikalsen ${ }^{2}$ \\ ${ }^{1}$ Norwegian University of Science and Technology, 7491 Trondheim, Norway \\ \{eric.monteiro, thomas.osterlie, parmiggi\}@ntnu.no \\ ${ }^{2}$ SINTEF Digital, Postboks 4760 Torgarden, 7465 Trondheim, Norway \\ marius.mikalsenesintef.no
}

\begin{abstract}
Processes of quantifying the qualitative have deep historical roots that demonstrate their contested nature. The ongoing push for Big Data/data science presupposes the quantification of qualitative phenomena. We analyse an ongoing case where the core of the qualitative - judgements, assessments, sensemaking - is being challenged by quantification through Big Data/data science-inspired new digital tools. Concretely, we study how traditionally qualitative sensemaking practices of geological interpretations in commercial oil and gas exploration are challenged by efforts of quantification driven by geophysical, sensor-based measurements captured by digital tools. Drawing on Wylie's notion of scaffolding, we outline three aspects of the performativity of scaffolding underpinning geological sensemaking: scaffolding is (i) dynamic (evolving with additional data, quality assurance, triangulation), (ii) provisional (radically changed when faced with sufficiently inconsistent data) and (iii) decentred (in and through distributed, loosely coupled networks of practices). In our analysis, the quantitative does not unilaterally replace the qualitative; there is an irreducible, reciprocal relationship. Yet, there is scope for significant changes in the role, location and sequence of tasks of quantification within the qualitative as we reflect on by way of concluding.
\end{abstract}

Keywords: Scaffolding, Performative, Post-Humanist, Sensemaking, Big Data.

\section{Introduction}

There has historically been a push for the quantification of qualitative phenomena [1]. To illustrate, the joint development of instruments and measuring scales during the 18th century transformed temperature from 'hot' (qualitative) to ' $50^{\circ} \mathrm{C}$ ' (quantitative) [2]. Some areas, however, have remained stubbornly beyond the reach of this transformation. The judgements, interpretations, and sensemaking involved in a host of knowledge-based professional work - the very heartland of the qualitative - has till date largely evaded quantification [3]. Big Data/data science, with its emphasis on data-driven, statistically based machine learning approaches, presuppose quantification. This raises the fundamental question whether the inability of quantification to 
make inroads into the heartland of the qualitative will prevail, or that the quantitative/qualitative boundary will be (radically) redrawn.

There are sound arguments for both views. On the one hand, data-driven approaches are already performing tasks well within what was until recently safely within the realm of the qualitative. Automated language tools, once identified as the acid test of 'intelligence' hence involving qualitative judgement, now 'work' in ways AI in the 1980 and 90s never did [4]. On the other hand, there are scholars underscoring the irreducibly qualitative. Leonelli et al. [5, p. 194], for instance, call for critically questioning "why, how, for whom, and when data are perceived as available, portable, and/or meaningful."

Against a backdrop of increasingly ideologically poised discourse, we adopt an empirically open stance. Somewhat simplified, current discourse oscillates between two extremes where Big Data/data science either spells the end of the qualitative and hence eliminate large swathes of human labour [cf. 3, 4] or views where the heartland of the qualitative can never be quantified [6]. Rather than hurling philosophical bricks, we approach the limit for quantification of the qualitative as an issue to be addressed empirically. As a first step, we pose the research question: How to theoretically characterise practically working quantification of qualitative sensemaking? Introducing Wylie's [7, 8, 9] concept of scaffolding and drawing upon post-humanist theorizing $[10,11,12]$ to elaborate upon the performativity of scaffolding sensemaking, we argue that there is no necessary opposition between the quantitative and qualitative. Rather, based on ongoing, longitudinal engagement with industrial geoscience exploring for commercial oil and gas resources, we show how the quantitative and qualitative recursively draw upon and implicate each other.

Industrial geoscience exploring for oil and gas resources is well-suited for investigating the tensions, conflicts, and strategies implicated in efforts promoting quantification into traditionally qualitatively oriented practices. Heavy investments in Big Data capabilities throughout the oil and gas industry [cf. 13] add weight to these efforts, but also actualise a standing debate within the geosciences between the two key epistemic communities [14] involved: geophysics and geology. With its background in natural history [15], geology is deeply tied to narrative (i.e. qualitative) understanding of the geological processes resulting in today's situation. Geophysics, on the other hand, is inseparable from its origin in physics-oriented quantified approaches to describing the subsurface as is. Proponents of natural scientific approaches to geosciences has criticised geology for lacking proper methodological grounding, and that a host of epistemic problems undercut its claims to knowledge: incompleteness of data, lack of experimental control, and the great spans of time required for geological processes to take place [16]. Focusing on the hermeneutic nature of geology, rebuttals of this critique [17] highlights the prominence of judgements, interpretation, and sensemaking involved in geological reasoning, the practical application of geology. That the tools supporting the ongoing digital transformation of commercial exploration for oil and gas are heavily biased towards the epistemic practices of geophysics rather than geology further challenges geology's role in future oil and gas exploration.

Drawing on Wylie's concept of scaffolding [7, 8, 9], we analyse the sensemaking involved in producing, backing up and justifying geological interpretations of the 
subsurface - the lifeblood of industrial geoscience. Unfolding as a tension between qualitative impulses and quantified imports, we analyse the performativity of scaffolding in line with post-humanist perspectives [11]: scaffolding is dynamic, provisional and decentred. If you accept the inherent relationality, hence irreducibility, of the qualitative/ quantitative, there is significant scope for transforming the scope, role and location of qualitative tasks as we reflect on in the conclusion.

\section{Theoretical background}

The novelty of Big Data tends to get inflated. Working with large data sets certainly is not new. Many sciences have a long history of dealing with large quantities of data, whose size and scale challenge available strategies and technologies for data collection, sharing, and analysis [18]. The novelty of Big Data, rather, lies in the scope, depth and scale of the methods, technologies and infrastructures to retrieve, accumulate and algorithmically manipulate data. Consistent with a historical perspective, Big Data in our analysis is but a vivid and empirically relevant expression of the longstanding efforts towards quantifying quality.

Some see Big Data as the complete 'conquering' and unilateral replacement of the quantitative over the qualitative insofar as arguing for a new era of empiricism [19, $20,21]$. Pure empiricism, i.e. quantification taken to the extreme, however, is met with stark criticism [6]. First, data is always shaped by the technology and platforms used, ontologies employed, and sampling bias. Organisations are dealing with structured, semi-structured and unstructured data from in and outside the enterprise. Variety comes in the form of user-generated text, images and videos as well as a variety of sensor-based data. Second, the algorithms used to capture certain kinds of data arose and were tested within existing scientific tests of validity. Assessing the veracity of data, i.e. the credibility and reliability of different data sources, is also an issue. Third, the idea that data can speak for themselves assumes that it is possible for anyone with a reasonable understanding of statistics and the right tools to interpret them without domain-specific knowledge, effectively ignoring effects of context, culture, policy, and governance.

Knowing with big data therefore does not simply amount to gathering data or 'evidence'. Data "are always already 'cooked' and never entirely 'raw" [2, p. 2]: they must be processed to count as evidence. Such processing involves informal and often unacknowledged social and technical routines. In a study of a 30-year effort to gather data to develop knowledge about HIV/AIDS, Ribes and Polk [22] describe how maintaining subjects' commitment to contribute data over time involved updating subjects with relevant information regarding the progress of knowledge about the condition and conducting sustained persuasion campaigns lobbying for subjects' continued participation. Similarly, Edwards examines data gathering informing climate change research and reports that measurement devices such as thermometers must be constantly calibrated to ensure the validity of their readings [23]. Procedures of verification are essentially collective organization-based exercises that invoke credibility [24]. Data quality thus involves not only creating but also maintaining procedures. In 
fact, it is precisely when grappling with uncertain and partial knowledge that it is crucial to legitimise and justify interpretations to make them credible and not mere guesswork.

Wylie's $[7,8,9]$ scaffolding concept offers a promising way to theoretically characterise practically working quantification of qualitative sensemaking involved in industrial exploration for oil and gas. Her notion is drawn from her extensive study of practices of archaeology, a domain strikingly similar to our case of geology: knowledge is partial, provisional, fallible and influenced by the arrival of quantified measurement techniques (including ${ }^{14} \mathrm{C}$ isotope decay, lead isotope analysis, dental enamel for oxygen isotopes). Scaffolding of archaeological knowing "build, and continuously rebuild, credible background knowledge" to develop and mobilise meaningful interpretations of the material evidence, juggling with several interpretations (or working hypotheses) at the same time. Currie [15] further expand upon the notion of scaffolding, arguing for its centrality in all historical sciences (counting, among others, archaeology, geology, and palaeontology). Consistent with a performative and relational perspective $[10,12]$, scaffolding is never reified but is dynamic, open to multiple interpretations and evolving [7]. Scaffolding is decentred and plays out in and through material-discursive practices [11]. Finally, different from an inherent opposition between qualitative vs. quantitative, a scaffolding perspective underscores their constitutive entanglement ${ }^{1}$.

\section{$3 \quad$ Research methods}

This paper reports from a longitudinal industry/university research collaboration on digital innovation in the oil and gas industry in the North Sea region. The particular activity we report from is based on the shared observation of both operators and vendor companies in the consortium that the existing digital toolset - which is predominantly measurement-based - is not always a good match for the exploration geologists' work practices. While this is fairly well known within the industry, the problem has proven intransigent to resolve. As such, the problem and its resolution are of both practical and scientific interest.

In line with principles of engaged scholarship [26], we are therefore conducting collaborative basic research with key stakeholders in the research consortium to explore and together with the stakeholders possibly resolve the problem. We draw upon the authors' combined research on the topic, which is to a certain degree traditional interviews (21 interviews with industrial exploration geoscientists, 1 interview academic geologist, 17 data managers in one oil company), but also field notes from 10 project workshops and informal conversations in a joint effort of understand and explain the discrepancy between geologists' work practices and the digital tools available to them. This work has been conducted against the backdrop of the author team's sustained engagement with the oil and gas industry over the past twenty years.

\footnotetext{
${ }^{1}$ Phrased in the vocabulary of paradox theorists [25] this amounts to recognising scaffolding not as a dualism ('either-or') but as a duality (allowing both)
} 
The empirical case we present is theoretically sampled to reflect three key aspects that have so far made the digitalization of knowledge work arduous to come by in exploration geoscience: 1) the data-driven nature of exploration work, i.e. a dependence on data to make sense of the inaccessible subsurface reservoir; 2) the irreducible uncertainty associated with the lack of access to the physical referents; 3 ) the importance of the continuous work to maintain and (re)interpret the data. Our data analysis is based on a working assumption that the transformation of data-centric knowledge work from qualitative assessments into quantified tasks performed within digital systems is not simply a matter of automation. Rather, it is generative of new phenomena whose potentials should be explored [27]. We have explored this through writing and discussing intermediate results multiple times with different industry stakeholders as well as academic representatives of the geosciences. The insight gained through these discussions has in turn been fed back into the analytic process.

\section{$4 \quad$ Scaffolding interpretation in oil and gas exploration}

Exploration for new oil and gas resources in the North Sea region has become increasingly digitalised over the past few decades. Where exploration for new resources used to be organised around offshore operations - initially through brute-force prospecting by drilling wells into the seabed, and later by collecting seismic data on subsurface formations - exploration is turning into mainly a data-intensive endeavor. Integrated cross-disciplinary exploration teams ${ }^{2}$ work together on interpreting available exploration data to determine if and possibly where to drill exploration wells in an assigned geographical area. Organised in projects, the process of assessing an area consist of three sequential, but overlapping steps:

1. determining whether or not the likelihood of finding commercially viable reserves in the area is high enough to warrant investing in exploration well drilling,

2. assessing existing and identifying new potential prospects for drilling exploration wells in search of new oil and gas resources, and

3. ranking the identified exploration prospects into a prioritized list of wells to drill.

Exploration data are inherently underdetermined. A common expression among explorationists goes something like 'We really know nothing for certain until we drill a well, and then we only have knowledge about the well'. The underdeterminedness of digital exploration data plays out along multiple dimensions; they are partial in geographic coverage and phenomena measured, of varying quality due to heavy reliance on sensor data of varying accuracy, and inconclusive in and of themselves.

\footnotetext{
2 These team as colloquially referred to as ' $G \& G$ ', a shorthand for geology and geophysics, the predominant professions in such teams. However, exploration teams also draw upon resources from other specialized professions such as petrochemists, paleobiologists, and structural geologists, to mention a few.
} 


\subsection{Scaffolding geophysical interpretation}

Seismic cross-sections form the backbone of exploration projects (Fig. 1). They are visual snapshots of the geological layering in a slice of the Earth's crust. They are a product of seismic interpretation. While G\&G experts working in interpretation software produce these visualizations, cross-sections are the product of a distributed machinery of quantitative processing and analysis methods along with stages and phases of manual inspection, cleaning, and massaging of different datasets. Emphasizing this distributed machinery brings out the scaffolding of seismic interpretation.

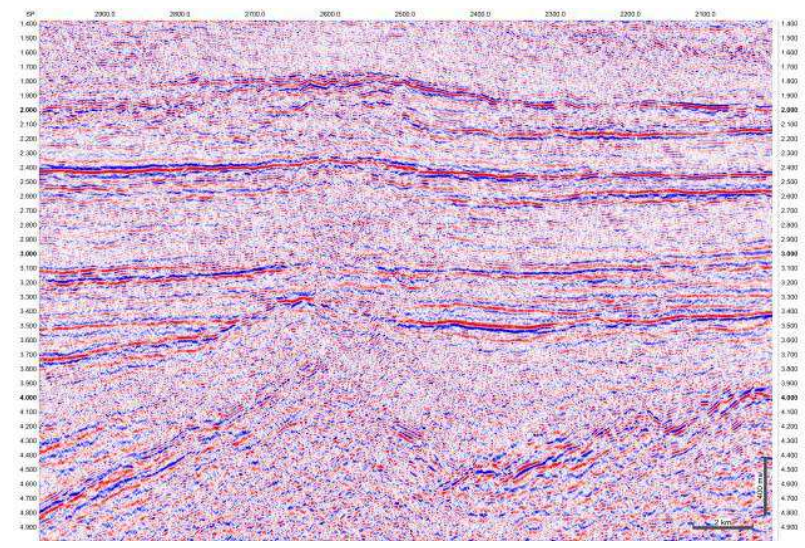

Fig. 1. Seismic cross-section. Continuous blue and red lines indicate geological layers in highquality area of the picture. More pixelated areas of the picture are indicative of poor seismic. Source: DISKOS, national data repository for the Norwegian oil and gas industry.

Seismic cross-sections are reflections of sound waves driven into the seabed and picked up by a long line of hydrophones (digital acoustic sensors) trailing behind a survey ship. Survey equipment configuration (the angle sound waves are driven into the seabed, what types of hydrophones used and their configuration in the trail) varies between surveys depending on the subsurface structures and phenomena expected to be found in the area. Transforming data of reflected sound waves into quantified properties of the subsurface that can be visualised in cross-sections involves a series of methods and techniques to correct for common errors in data generation, removing noise, enhancing signals and transform time-based sound data into spatial representations of the subsurface. This scaffolding of seismic data involves manual cleaning and preparing of the data:

Ships never travel in a straight line. And we have to compensate for wave height. Not only do waves dynamically change the distance between hydrophones and seabed. Waves ripple through the hydrophone array over time, so different hydrophones are at different heights from the seabed as the different reflections reach the surface. This is more complex, and is usually done by signals geophysicists by hand. (Field interview, geophysicists) 
Exploration projects rarely draw upon only a single seismic data set. Rather, they combine seismic data of the area under investigation with data from a wide array of different company internal as well as publicly available data sources. These may be old seismic data from the same area, from adjacent areas, or other data sources such as well $\operatorname{logs}$ (detailed measurements of geological formations along the trajectory of a well), old reports, or even existing models from previous efforts to find oil. Project data managers (PDMs) collect data from the various sources, preparing and importing them into project files explorationists can load onto the seismic interpretation software. This involves a lot of manual inspection, cleaning, and transforming of data files. A situation from our fieldwork, where we sat down with a PDM that walked us through the process of loading well data into an exploration project, exemplifies this. Loading well curve data into a project, she checked the calibration of the well data to determine if it was measured in calibush or mean sea level. "This matters, because if you do not get this calibration right, you skew the well path with 20-25 meters, and that is unfortunate," she said laughing. She also made sure that the curves that were loaded for a well looked they way it was supposed to do. Each curve had a template for how they are to be displayed. For some curves, the values should be 0 or 1 , true or false. For other curves the value should be between 0 and 100. Different min and max values that are actual for that curve. If there is a mismatch, it is typically because the curve has the wrong name, she explains. Different vendors name the curves differently, one company can have one name for a curve, and another company has the same name for a different curve. After loading the data, the PDM displayed the data and did a manual inspection verifying that the data seemed about right.

Over decades, oil companies have gone through a series of databases to archive exploration data. One PDM referred to herself as the octopus spreading her tentacles through legacy databases in order to draw together the disparate datasets. Before importing seismic data into a project, the PDM will quality check the data. This can be particularly challenging with old seismic surveys:

-I will first look through the raw data file. Having worked with this for so many years, I know exactly what the file should look like. If I see any errors, I will see if I can correct them. To do that, you basically have to know exactly the kind of equipment used in shooting the survey, down to the minutest details of particular hydrophone designs. I does help having been in the game a while to do that. (Interview, PDM)

\subsection{Scaffolding geological interpretation}

It is not possible to tell from a seismic cross-section whether or not there is an oil reservoir in an area. To do so, explorationists need to establish the presence of an active source rock (i.e. a layer of organic matter that pressure and temperature have transformed into hydrocarbons at some point in time), a geological formation that can trap the hydrocarbons to prevent them from seeping to the seabed and disappear, and a path within the subsurface leading the hydrocarbons from its place of origin to the trap. This cannot be told from cross-sections alone. Seismic data measures the bound- 
ary between different geological layers, but tell little about the geological composition of the layers: whether they are sandstone, shale, chalk, and so on cannot be determined from the data. Furthermore, seismics are well suited to measuring rock properties, but do not measure whether or not geological strata contain hydrocarbon deposits. Exploration companies address the shortcomings of seismic cross-section in many ways, but the most common approach in exploration projects is to hand the initial seismic interpretation (in form of cross-sections) over for geological interpretation.

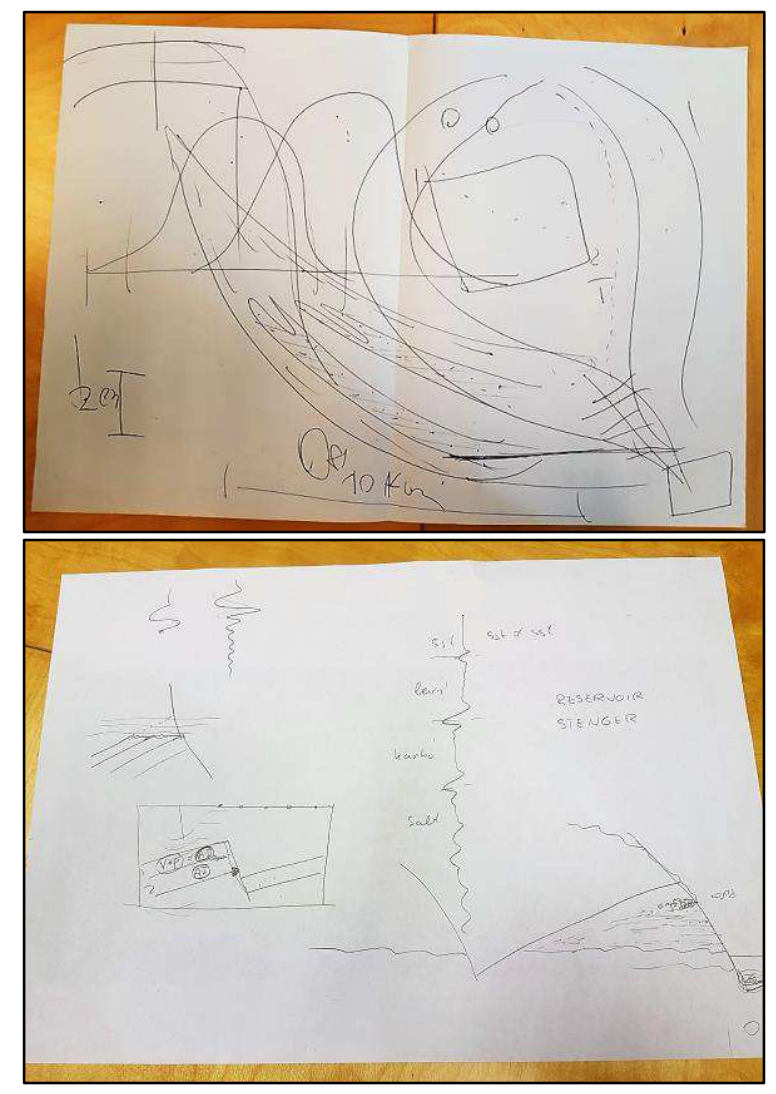

Fig. 2. Hand drawings made by exploration geologists during interviews. Top: the drawing was used to re-tell the creation and modification of different geological histories while making sense of a prospect. Bottom: the drawing supported the explanation of the subsurface stratigraphy and how porosity could be used to interpret a geological formation. Source: pictures by the authors.

We learned early on to have pen and paper ready when interviewing exploration geologists. They would quickly as 'Do you have a pen and some paper?' when starting to talk about geology. Thematising this with the corporate chief geologists, he affirmed: -Geology is very pictorial (Fig. 2). Geophysicists, on the other hand, showed little or no interest in drawing to explain their work. Indeed, when we pointed this out to more data-oriented geophysicists they would somewhat condescendingly refer to geologists 
as 'artists who like to draw' or even as a 'dying breed' implying that data-oriented quantitative approach to geo science is, as one geophysicist put it, 'explorationists for the digital age'. Geologists would scoff or even bristle when confronted with such statements.

Bracketing these professional tensions, we view them as expressions of how geological interpretation scaffolds exploration data distinctly different than seismic interpretation. The exasperation of a geophysicist offers a point of entry into this:

-It is quite annoying, you know, when you have spent weeks calculating exact uncertainty ranges [for the seismic horizons], and the first thing the geologists do is to say "let's get rid of the uncertainties so we can start working'." (Field note excerpt, conversation with geophysicists)

Seismic interpretation scaffolds exploration data to represent the subsurface as it is today. Geological interpretation, on the other hand, is a theory-methods conglomerate oriented around understanding the structure of the subsurface in narrative terms; narratives of geological processes and events, their sequences and timing, how they unfold and transform the geology over millions of years. It approaches the layers of a seismic cross-section as indicators of geological processes and events.

-Geophysics is given too much emphasis in exploration. Their [the geophysicists'] interpretations need to be grounded in geological understanding. That is why so many exploration wells are dry. (Geologist working with a software vendor, field notes excerpt)

The geologist's reference to 'geological understanding' illustrates how geological interpretation performs a more conceptual scaffolding. Rather than being neatly stacked, geological layers are usually jumbled and mixed, as geological processes and event cover traces of past geological processes and events in layer upon layer of sediments. All of this is evidence to be used actively in geological interpretation.

-If you have something like this, says the geoscientist trying to explain the limitations of seismic cross-sections in providing a proper picture of the subsurface. Drawing two triangular shapes on a piece of paper, she continues: This shape can indicate two distinctly different processes. Either the slope here, she points to the bottom-most triangle, indicates erosion. Then the topmost structure is sedimentation on top of it. Or, the reason for this shape is that this (pointing at the shared diagonal between the two triangles) is a rift and the topmost layer has slipped under the other layer. In this case, we may have a migration path. Or the whole scenario may be because of sedimentation losing momentum and therefore creating a triangular shape that has been pushed up.

Drawing upon a wide array of methods of knowing the "deep past" with scant and usually degraded evidence, geological interpretation seeks to establish a narrative of geological events and processes that could have led to the situation of today. In so doing, they seek to verify whether or not the area has an active source rock, a trap, a migration path, and that the timing of geological events is such that hydrocarbons migrating from the source rock have been caught by the trap. This is a process of 
cycling back and forth between seismic and geological interpretation. Seismic images are rarely so of such a quality that it is obvious to explorationists how the subsurface is today:

Using his pen to follow a clear red line in the pixelated seismic mage, the geologist explains: "This horizon is fairly clear. We can distinguish this as the border between two geological borders clearly. But here, you see, it is much harder to distinguish the horizon." At this stage he has reached what occurs as a sea of red and blue pixels in the seismic cross-section. "Here the signal is no longer any good, and we can hardly discern any boundaries." (Field interview with academic geologists teaching seismic interpretation)

\section{The performativity of scaffolding}

The central problem in oil exploration, starting from measured observations of geophysical properties of the geological formation as evident today, is to tie these to an inferred, narrative account of the rich, geological processes (erosion, sedimentation, tectonic plate movements, diagenetic processes, faults, etc.) that could have yielded the current situation. Making sense thus involves the entanglement of the quantitative (measurements, IoT generated data) with the qualitative (narrative of the geological processes). Data about the current geological situation come from measurements subsequently manipulated algorithmically (in the case of seismics, by several non-linear filters whereby only less than $1 \%$ of the original data is kept) that need a narrative hence qualitative contextualizing. The sensemaking amounts to working backwards, from the data, to a geological narrative capturing the processes whereby the current geophysical measurements could have resulted. There is no opposition between the quantitative and the qualitative. Rather, they recursively draw on and implicate each other. Drawing on Wylie's notion and post-humanist theorizing, the scaffolding of sensemaking in oil exploration is performative. With basis in this, we will now proceed to discuss a theorization of practical working quantification of qualitative sensemaking with the push for big data in oil and gas exploration.

First, scaffolding is dynamic. In her work on interpreting material data in archaeology, Wylie [8] describes in strikingly similar way this 'reverse engineering' of a narrative understanding from measured data observed at the archaeological site. "Archaeological facts", exactly like facts in oil exploration, grapple with the problem "that the tangible, surviving facts of the record so radically underdetermine any interesting claims archaeologists might want to make that archaeologically based 'facts of the past' are inescapably entangled with fictional narratives of contemporary sensemaking." [9, p. 301] This, as Wylie [9, pp. 308-309] (emphasis added) goes on to argue, "shows how detailed histories of the travel of these [data] collections, records and interpretations $(\ldots)$ can play a critical role in the process [of] (...) grounding the adjudication of their epistemic integrity as a basis for framing factual claims about the past (narrative facts)."

In oil exploration, we find a similar form of reverse engineering. For instance, Section 4.2 describes how geological interpretation builds and supplement early seismic 
cross-sections with a narrative understanding of the area's geological composition. Deposition environment models - idealised models of the processes through which geological layers have been deposited over time in a geological region, and the subsequent composition of each layer's masses - are one of several data sources used in understanding the composition and layering of geological strata in a seismic crosssection:

-The seismics only show me the border between geological layers. A drilled well tells me quite exactly the composition of the rocks in each layer, but only for the width of the well. If the depositional environment were a desert, I would know that there was a continuous sand layer [to contain hydrocarbons] here. But if the depositional environment were a delta, for instance, I would know that it does not have a continuous mass of sand throughout the entire width of the layer. Sediments deposited by the rivers [flowing through the delta and into the ocean] will be formed into shales cutting through the reservoir. (Exploration geologist, field note excerpt)

As such, geoscientists make sense of the subsurface through successive geological and geophysical approximations of the subsurface. Drawing upon Chang's [2] history of quantification of temperature, Chapman and Wylie [7, p. 5] describe 18th century chemists' use of 'successive approximations' in ways much similar to interaction between geophysical and geological interpretation: "chemists relied on assumptions and methods they knew to be faulty but that made it possible to refine their understanding of the phenomenon of temperature to the point where they could eliminate some initial hypothesis and articulate new, more sharply specified questions, questions that would require the construction of new scaffolding". Fully aware that early seismic cross-sections are mere approximations of the subsurface, geoscientists still use them for geological interpretation. Through geological interpretation they seek approximate narrative understandings of the subsurface that can inform further geophysical processing in the seismic interpretation software. Resulting analyses from this processing and a possibly revised seismic cross-section in turn inform further refinement and exclusion of possible geological narratives.

This is particularly apparent in the way geophysical and geological interpretation scaffolds and constitutes much the same data differently through a dynamic back- and foregrounding of aspects of the scaffolding. Geophysical interpretation scaffolds the data as representations of the subsurface as is. Geological interpretation scaffolds the data as traces, that is "downstream consequences of past events" [15, p. 10]. That is "how the world is depends how the world was" [15, p. 67] (italics in original). By constituting the seismic image and other exploration data as trace data, geological interpretation dynamically enacts a scaffolding where technical aspects relating to seismic processing and analysis is back staged. When the geophysicist in Section 4.2 laments how geologists ignore his hard-won statistical uncertainty ranges, they background these aspects of the scaffolding to constitute the data as traces. Yet, through such dynamically back- and foregrounding aspects of the scaffolding explorationists successively build an increasingly more refined understanding of the subsurface. 
Second, scaffolding is provisional. In archaeology as in the geosciences, there is significant competence in moving (hermeneutically, [cf. 16, 17]) between close-up, measured data points and taking a step back to gain an appreciation of the broader, formative processes: "[archaeologists] have built up a repertoire of research strategies specifically designed to mobilise the evidence of human lives and events that survives in an enormous range of material evidence...In the process, they have decisively enlarged, challenged, and reconfigured what we know, putting material evidence to work in the investigation of a great many different aspects of the cultural past." [27, p. 5]

Provisionality is most prominent in the way geoscientists formulate, compare, and analyse multiple and simultaneous geological narratives of the same seismic crosssection during geological interpretation. This is expressed through sketching of different scenarios, either by hand on paper and napkins or in the many PowerPoint presentations littering exploration project's shared folders. The previous example where the geoscientist considers different depositional models for the same area, and similarly the way the geoscientists in section 4.2 offers multiple interpretations of the same geometric shape, exemplifies such provisionality. A seasoned geoscientist stated during an interview:

-There is but one thing geologists like better than finding oil, and that is to drill a dry well. Dry wells are an opportunity to better understand the subsurface.

New, and in particular unexpected data such as a dry well, challenges geoscientists' assumptions about the subsurface, calling for a re-interpretation - a re-scaffolding - to integrate new data with existing understandings of the subsurface. The provisionality of scaffolding is here a matter of revisiting and challenging ideas and assumptions about the data and geological processes leading up to the existing situation in the subsurface.

Although dynamic and provisional, scaffolding exhibits a degree of path dependence. As described in Section 4.1, seismic data is generated (both generation of sound reflections and the processing) to bring out particular geological structures or phenomena expected to be present in the area. Seismic data is, as such, entangled with prior knowledge and assumptions of the subsurface. Similarly, often invisible in the final result, the painstaking work of setting up geophysical models illustrates the importance of the scaffolding in moving from pluralistic qualitative narratives supported by multiple sketches to a single geophysical model. Geophysical models are defined by a large set of metadata that codify the model's basic assumptions. The metadata shape practical model construction by constraining valid values for populating the model's three-dimensional grid with geophysical properties. As such, revisiting the model's basic assumptions based on new hypotheses (which emerged from the evolving scaffolding) after the modeller starts populating the grid requires significant rework of the entire model, and is rarely done in practice. This investment, however, comes with clear advantages in terms of comprehensiveness, thus complementing the qualitative narratives for specific purposes. Whereas geological narratives are purposefully pluralistic and non-constrained, the completeness of geophysical models 
imbues a sense of certainty of understanding. Quantification enables simulation and formal verification in ways not possible with qualitative narratives. An in-depth look into this shifting relation between qualitative narratives and quantified models is useful to understand how predefined structures (e.g., metadata) become part of the scaffolding of the explorationists through practice. Although such structures are simplified typologies that are often hard to debunk, they are an essential basis to their conceptual scaffolding, acting as "a medium of communication" and a "framework for systematizing" data management "precisely because they reduce complexity" $[8, \mathrm{p}$. 213].

Even though scaffolding stabilises, and necessarily so, over the course of an exploration project, explorationists strip away existing scaffolding when revisiting exploration prospects they have previously investigated. Sometimes this is a matter of practicalities:

-We don't know the thinking behind the old project's interpretation, so it is easier to start from scratch than to try to reconstruct it. (Explorationist, interview)

At other times, such as when re-processing old seismics, most of the scaffolding is stripped off as basic assumptions about the data or area under investigation are revisited. Seismic data is always collected and processes in order to bring out structures and phenomena expected to be present in the subsurface (see Section 4.1). Exploration companies have therefore increasingly turned their attention to pre-processed seismic data, subjecting the data to alternative processing techniques in hopes of bringing out previously unseen geological formations that can provide clues to the presence of new oil and gas resources.

Third, scaffolding is decentred. Contrary to an actor-centric understanding of sensemaking, we adopt a post-humanist perspective one. We thus analyse the decentred, distributed, sociomaterial practices that go into sensemaking. As Hultin and Mähring [11, p. 572] point out, "[a]s agency is not attributed to actors but continuously flows through material-discursive practices, the 'who', the assumed subject or being, is constituted by the "how"'. Chapman and Wylie [7, p. 55] alludes to the decentred nature of scaffolding in describing fieldwork as "a process that depends on the development of scaffolding in the form of technical expertise and community norms of practices which are internalized by individual practitioners as embodied skills and tacit knowledge, and externalized in the material and institutional conditions that make possible the exercise, and the transmission of these skill and this knowledge". Forefronting the performativity of scaffolding further expand upon this.

Scaffolding decentres geophysical interpretation from explorationists working in seismic interpretation software on their workstations to the spatially and temporally distributed processes of producing, processing, cleaning, and preparing data (Section 4.1). As such, seismic cross-sections (one of geophysical interpretation's key outcomes) are the effect of data circulating through networks of sociomaterial practices. These practices reside along the continuum from fully automated, black-boxed computerised processing to more manual practices of filtering, sorting, massaging of data (e.g. PDMs cleaning and preparing data for explorationists). One of the PDMs inter- 
viewed described this continuum when explaining how errors occur as well data flows through a sociomaterial network:

-A typical error [in a well $\log$ ] occurs in the file headers. Sometimes it happens that they copy and paste a file somewhere else, and one file is modified locally, then the error is left there, if no one remembers to update it.

While some of the processes of circulating data through this network are linear (as in repeated in stable patterns, such as sequence of generating seismic reflections followed by standard processing techniques to correct for common errors in data generation, removing noise, enhancing signals, transform time-based sound data into spatial representations of the subsurface), the network of sociomaterial practices is rhizomatic and non-linear in nature. Explorationists are very clear on exploration project's contingent nature:

-It is difficult to give a clear sequence of activities [in an exploration project]; it all depends on the data, what we expect to find, what we actually are able to find, the work plan we are committed to, and so on. (Geologist, field note excerpt)

Pursuing the performativity of scaffolding through the distributed processes of geophysical and geological interpretation brings out how scaffolding unfolds within a loosely coupled sociomaterial network of fluid agency. Many geoscientists we have talked with talk of this non-linearity in terms of analogical reasoning:

-You see this curved shape, and it reminds you of a river bend. So you look for current examples of such bends to see what kind of deposition environment that can be. You find the shape is typical of rivers flowing through jungles and mangroves, so then you can work on the assumption that the shape you see has been deposited in a jungle environment. (Chief geologists, field note excerpt)

\section{Conclusion}

As our historic outline indicates, the relationship between a qualitative phenomenon and its quantified rendering is contested and conflictual. The 'macro' picture of a gradual quantification of the qualitative downplays to the level of non-existence the 'micro' level set-backs (reverse salient) and opposition to efforts of quantification. Against this backdrop, the proclamations for a new 'era of empiricism' (hence quantification taken to the extreme) or data with 'no theory' come across as exactly that, proclamations.

The practices of sensemaking we analyse - constructing geological interpretations from patchy, faulty and indeterminate data - represent the heartland of qualitative ingredients of knowledge work: judgement, assessment, evaluation [3]. The trajectory of efforts of quantification in our analysis, however, is anything but smooth and unidirectional. Drawing on the performativity of scaffolding, we demonstrate a thorough entanglement - reciprocity - between the qualitative and the quantitative. 
The inherent reciprocity between quantitative/ qualitative should not be taken to suggest that their boundary and relationship remains stable. The precise role, location, extent and sequence of quantified renderings within the traditionally qualitative domain of geological interpretation are subject to ongoing challenges and changes, not the least from big data/ data science methods. Selected pockets or tasks, once accomplished by qualitative judgements, are through new digital tools quantified and automated. For instance, the tracing of horizons in a seismic cross-section is now functionality in the current digital tool for seismic interpretations. Selected geological objects such as faults may be identified from the initially undifferentiated seismic image. Drawing the line for what qualitative phenomena and tasks are amendable (or not) for quantification from also big data hence shifts over time and needs to be empirically analysed [28].

\section{References}

1. Crosby, A.W.: The Measure of Reality: Quantification and Western Society. Cambridge University Press, Cambridge, UK (1997).

2. Chang, H.: Inventing Temperature: Measurement and Scientific Progress. Oxford University Press, Oxford, UK (2007).

3. Autor, D.H.: Why Are There Still So Many Jobs? The History and Future of Workplace Automation. Journal of Economic Perspectives 29(3), 3-30 (2015).

4. Brynjolfsson, E., McAffee, A.: The Second Machine Age. W. W. Norton \& Company, Inc., New York, NY (2014).

5. Leonelli, S., Rappert, B., Davies, G.: Data Shadows: Knowledge, Openness, and Absence. Science, Technology, \& Human Values 42(2), 191-202 (2017).

6. Kitchin, R.: Big Data, new epistemologies and paradigm shifts. Big Data \& Society 1(1), 1-12 (2014).

7. Chapman, R., Wylie, A.: Evidential Reasoning in Archaeology. Bloomsbury Academic, London, UK (2016).

8. Wylie, A.: How Archaeological Data Bites Back: Strategies for Putting Old Data to Work in New Ways. Science, Technology, \& Human Values 42(2), 203-225 (2017).

9. Wylie, A., Chapman, R.: Material Evidence: Learning from Archaeological Practice. In: Chapman, R., Wylie, A. (eds.) Material Evidence: Learning from Archaeological Practice, pp. 1-20. Routledge, Oxon, UK (2015).

10. Barad, K.: Meeting the Universe Halfway: Quantum Physics and the Entanglement of Matter and Meaning. Duke University Press, Durham, NC (2007).

11. Hultin, L., Mähring, M.: How practice makes sense in healthcare operations: Studying sensemaking as performative, material-discursive practice. Human Relations 70(5), 566593 (2017).

12. Orlikowski, W.J., Scott, S.V.: Exploring Material-Discursive Practices. Journal of Management Studies 52(697-705 (2015).

13. McKinsey\&Company, http://www.mckinsey.com/industries/oil-and-gas/our-insights/thenext-frontier-for-digital-technologies-in-oil-and-gas, last accessed August 28/2018.

14. Knorr Cetina, K.: Epistemic Cultures: How Sciences Make Knowledge. Harvard University Press, Cambridge, Mass. (1999). 
15. Currie, A.: Rock, Bone, and Ruin: An Optimist's Guide to The Historical Sciences. The MIT Press, Cambridge, Mass. (2018).

16. Frodeman, R.: Geological reasoning: Geology as an interpretive and historical science. GSA Bulletin 107(8), 960-968 (1995).

17. Frodeman, R.: Hermeneutics in the Field: The Philosophy of Geology. In: Babich, B., Ginev, D. (eds.) The Multidimensionality of Hermeneutic Phenomenology, pp. 69-79. Springer International Publishing, Geneva, Switzerland (2014).

18. Gitelman, L. (ed.): Raw Data is an Oxymoron. The MIT Press, Cambridge, Mass. (2013).

19. Agarwal, R., Dhar, V.: Big Data, Data Science, and Analytics: The Opportunity and Challenge for IS Research. Information Systems Research 25(3), 443-448 (2014).

20. Anderson, C.: The End of Theory: The Data Deluge that Makes the Scientific Method Obsolete. WIRED, (2008).

21. Davenport, T.: Big data at work: dispelling the myths, uncovering the opportunities. Harvard Bussines Review Press, Boston, Mass. (2014).

22. Ribes, D., Polk, J.B.: Organizing for ontological change: The kernel of an AIDS infrastructure. Social Studies of Science 45(2), 214-241 (2015).

23. Edwards, P.N.: Global Climate Science, Uncertainty and Politics: Data-laden Models, Model-filtered Data. Science as Culture 8(4), 437-472 (1999).

24. Power, M.: The Audit Society: Rituals of Verification. Oxford University Press, Oxford, UK (1999).

25. Farjoun, M.: Beyond Dualism: Stability and Change As a Duality. Academy of Management Review 35(2), 202-205 (2010).

26. Van de Ven, A.H.: Engaged Scholarship: A Guide for Organizational and Social Research. Oxford University Press, Oxford, UK (2007).

27. Zuboff, S.: Big other: surveillance capitalism and prospects of an information civilization. Journal of Information Technology 30(1), 75-89 (2015).

28. Pearl, J., Mackenzie: The Book of Why: The New Science of Cause and Effect. Basic Books, New York, NY (2018). 